\title{
Competency-Based Approach to Educational Content for Sustainable Development in Latvia
}

\author{
Daina Vasilevska ${ }^{1}$ Dr.sc.admin.; Andrejs Geske ${ }^{2}$ Dr.oec. \\ Liepaja University, Latvia ${ }^{1}$; University of Latvia, Latvia ${ }^{2}$ \\ daina.vasilevska@gmail.com ${ }^{1}$; andrejs.geske@lu.lv²
}

\begin{abstract}
Sustainable development is a civilizational strategy recognized by the world community, within the framework of which environmental impact does not go beyond the natural possibilities. The transition to sustainable development is a complex and requires a change in the very foundations of social life. Education is essential in achieving sustainable development. An important role in the implementation of education for sustainable development belongs to teachers. For this, teachers must have appropriate professional competencies. The purpose of the study is to determine how well teachers are prepared for the changes themselves and whether they have enough knowledge to successfully implement this educational strategy in the process of teaching students in high school. As a result of the survey, it was shown that the ideas of sustainable development in the education system as a whole are perceived positively, but the urgent need is professional training and advanced training of teachers for their implementation. The article concludes with practical suggestions to strengthen teachers' educational capacities for sustainable development.
\end{abstract}

Keywords: teacher, education for sustainable development, competency-based approach.

\section{Introduction}

Education at any level is an essential component of the growth strategies of the Organisation for Economic Co-operation and Development (OECD) countries towards overcoming the economic crisis. To ensure the effective implementation of measures to improve the quality of education in the long term, it is necessary to provide all students with access to high-quality educational services, to contribute to the acquisition of skills, abilities and knowledge that they will need for effective integration into society and the labor market.

The concept of modernization of teacher education is based on the fact that it is the teacher who is intended to provide training and education for the younger generation at all levels of the education system, considering the realities of the present and future prospects for its development, ensuring modernization processes that are sustainable innovative development of the country. Sustainable is understood as such development that satisfies the needs of the present, but does not imperil the ability of future generations to satisfy their own needs, that is, in which the impact on the environment does not go beyond the natural capabilities (Transforming our world..., 2015).

The importance of introducing education for sustainable development has been emphasized over the years. In 2012, the UN Conference on Sustainable Development was held in Rio de Janeiro. Her declaration, "The Future We Want," contains a section on "Education," which emphasizes the need to expand educational systems in terms of training people to solve the problems of sustainable development (SD), including through improving teacher training (The United Nations..., 2012).

In 2013, the UNESCO General Conference formulated proposals for the Global Program of Action for Education for Sustainable Development (ESD) beyond 2014 (Proposal for a Global..., 2013). Teachers are one of the priority areas along with politics, a general institutional approach, youth and local communities. There is an urgent need to build the capacity of teachers, lecturers, instructors, educators, activist's voluntary pedagogical organizations and others capable to realize sustainable development face changes. To do this, ESD should be integrated into the training of teachers and administrators of formal, additional and informal education (enlightenment).

At the first stage, it was proposed to include the topic of ESD in specific subject areas, but then move on to implementing ESD as a cross-cutting topic. Sustainable development prospects should be more widely integrated into postgraduate education, advanced training and retraining (including corporate programs) of specialists, leading employees, government employees, business workers, and the media. 
State governments should create the conditions for the provision of training, professional training and advanced training for teachers and other education system workers in order to effectively integrate ESD. The ESD implementation roadmap provides among the expected results, in particular, the introduction of ESD principles in professional educational programs, the introduction of certification standards and an accreditation system in accordance with the concept of ESD (Ten years of..., 2016).

The main goal of education for sustainable development is that everyone would receive the appropriate knowledge and motivation to achieve and live in compliance with the principles of sustainable development. Education for sustainable development is designed to answer the question: what should students know and be able to do by the time they graduate from school, college, university, what knowledge and skills adults need to acquire in order to be as useful as possible to improve the quality of life and solve the problems of their community, including harmonization of relations between society and nature?

One of the key tasks for ESD is the development by teachers of knowledge that enables them to include sustainable development issues in the subjects they teach. Most schools in Latvia have a good experience of implementing environmental education. The Guidelines for Sustainable Education do not contradict the Environmental Education Guidelines, but take them in a broader context (Table1) (Hume, Barry, 2015; Rydén, Migula, Andersson, 2003).

\section{The main differences between environmental education and ESD}

\begin{tabular}{|c|c|c|}
\hline No. & Environmental education & Education for Sustainable Development \\
\hline 1 & $\begin{array}{l}\text { devoted to problems of the } \\
\text { environment }\end{array}$ & $\begin{array}{l}\text { considers environmental protection in a complex, efficient use of } \\
\text { natural resources, maintaining ecosystems that are successfully } \\
\text { functioning society and economics }\end{array}$ \\
\hline 2 & $\begin{array}{l}\text { at the core of environmental } \\
\text { problems - human activities } \\
\text { and their impact on the } \\
\text { environment }\end{array}$ & $\begin{array}{l}\text { the general issue is the contradiction between people goals: } \\
\text { environmental, social, cultural and economic }\end{array}$ \\
\hline 3 & in the spotlight - biodiversity & the focus on cultural, social, economic and biological diversity \\
\hline 4 & $\begin{array}{l}\text { purpose of action: an enabling } \\
\text { environment for generations }\end{array}$ & high quality of nowadays life and for future generations \\
\hline 5 & environmental action & lifestyle motivation is based on important moments of privacy \\
\hline 6 & $\begin{array}{l}\text { environmental education is } \\
\text { conducted in local and global } \\
\text { context }\end{array}$ & $\begin{array}{l}\text { ESD should be applied and based on local economic, social, cultural } \\
\text { and environmental conditions and communities, followed by } \\
\text { regional, national and global context }\end{array}$ \\
\hline 7 & taught within individual items & Integrated in all aspects of teaching, learning and school life \\
\hline
\end{tabular}

A reform of the content of school education "School 2030" has begun in Latvia, which will affect preschool, primary and secondary education. It is gradually being introduced at the pre-school education level and in the first grade, from September 1, 2019, it will concern primary schools, and from September 1, 2021 - secondary education (National Reform..., 2019).

A competency-based approach to education is based on the principles and values that underpin sustainable development; takes into account all three aspects of the environment (nature, society and economics); based on lifelong learning; finds a compromise between evolving nature and the concept of sustainability; enhances civic engagement, greening governance, improving quality of life; It is interdisciplinary, provides the integration of various academic disciplines, traditional and innovative training programs.

Summarizing the conclusions of a number of researchers, it can be assumed that education for sustainable development is the process and result of forecasting and the formation of human qualities (knowledge, skills, relationships, competencies, personality traits, the style of people and communities), providing an increase in the quality of life within the natural capacity of natural ecosystems (LiceZikmane, 2018; Cyrankowska, Kostecka, Mazur-Paczka, 2019). 
Since none of us knows what life will look like in a future society, it is not possible to give ready-made recipes for life, but a teacher can help students learn to think independently. It does require a re-evaluation of teaching approach. Teaching for sustainable development requires the teacher to be independent in judgment, open and flexible thinking, readiness to perceive with each new look, the ability to distinguish between facts and judgments, willingness to reconsider his judgment and nonreceptive decisions as final and unchanging; have the ability to help students become so.

Education for sustainable development should consider that the learning process should be learnercentred (based on the learner's experience and questions), processes (focus on regularities), action (develop action competence), assessment (promote critical thinking and position), society (involve students in identifying and addressing real problems) and addressing issues holistically (including economic, environmental and social aspects).

The main task of the authors was to find out how teachers themselves evaluate their level of preparation for implementing the objectives of education for sustainable development.

\section{Methodology}

The study uses data from a survey conducted by the Education and Information Services of Riga City. The authors participated as consultants in the design and analysis of the survey. The EDURIO survey platform (edurio.com) was used to create the survey.

The survey took place from May 2018 and was attended by teachers from 12 schools in Riga. The survey was completed by 217 teachers. The survey consisted of 20 questions on various aspects of the implementation of sustainable education. The survey included both open-ended and closed items. Teacher responses were assigned numerical values (5-excellent, 4 - very good, 3 -good, 2 - fair, 1 - poor) and calculating the average from these values. Data are given as a percentage of the total number of respondents. The Likert scale was used for fixed response items, with responses ranging from 1"no" to 5 "yes". Data analysis and processing was done using Microsoft Excel 2010 charting software for simpler calculations and IBM SPSS Statistics 24.

The questionnaire does not contain information about respondents (age, gender, length of service), so the impact of these factors on the results will not be addressed in this research, although it is likely to exist.

\section{Results and Discussion}

Currently, the world community has become aware that it is education that plays a vital role in improving the relationship between man and the environment. And in this sense, the "ecological" model of education is quite real, which, however, cannot be reduced only to the model of environmental education, since it is absolutely obvious that none of the viable solutions to environmental problems can be implemented without changes at all levels of education. Environmental education alone will not solve the environmental problem if it is divorced from other types of education. However, as well as the solution of the environmental problem, in principle, it is impossible without a positive shift in the whole complex of global problems. A person, as a rule, the more educated he is, the more likely he is to take actions to ensure environmental safety. It is no coincidence that the highest level of environmental awareness is observed among the most educated part of the population - the intellectual elite. In the interests of sustainable development, it is the pedagogical community that must ensure the continuity of education at all its levels: from preschool to higher education and for adult education, including formal, additional and non-formal education.

Under this context, greening is supposed to solve problems of overcoming various kinds of crises of the global world on the basis of the formed "life position, values and environmental culture as an integral part of the general culture of the world that incorporates universally recognized human values and human forms" (Policy Document for..., 2015). In this context, education for sustainable development can contribute to the formation of the worldview of the individual; building a general picture of the world; education of deep morality through universal values. This raises the question of what is the real situation with the understanding and acceptance of this phenomenon by the pedagogical community.

In order to answer these questions, a study was conducted among Latvian teachers. 
Most of the respondents (74.1\%) are aware of the need to implement ESD in all educational institutions, at all levels of education. The main sources of information in this case are pedagogical publications $(27.1 \%)$ and other mass media $(25.9 \%)$, colleagues $(15.3 \%)$, the administration, and the management of an educational organization $(15.0 \%)$. Some $(13.4 \%)$ learned about this during domestic and foreign conferences, seminars, internships, and refresher courses.

Only $3 \%$ of teachers are familiar with the educational documents for sustainable development at the international level. Only $2 \%$ of teachers defined education for sustainable development. $13 \%$ of teachers answered that education for sustainable development can change the world, what is needed for this: to formulate goals specifically to obtain real results for sustainable own development, development of the school, local community; study the theory of SD; enrich the content with ideas of SD; improve methods, educational technologies for sustainable development; encourage the need of students in selfeducation, self-realization, while creating the necessary conditions.

In the vast majority (79.1\%), teachers positively assess the need for ESD (17.9\% found it difficult to answer, no negative answers). Among the reasons for the importance of ESD are the conservation of the biosphere and life on the planet; the survival of mankind, the possibility of the existence of future generations; the need for a prudent attitude towards natural resources; conservation of the world, harmonious, co-evolutionary development of man and the environment (nature, society, economy); the need to create environmental awareness and increase the level of ecological culture of citizens, the diverse development of the personality of students, the modernization of education in general (integrated approach, innovative forms of training, modern pedagogical approaches and methods, project method).

The following may be referred to such methods: heuristic conversation, "brainstorming", role-playing and "business" games, trainings, case-method, project method, group work with illustrative material (Learning for the future..., 2012).

Teachers are a real driving force for change. They using various educational methods and activities and capable the promotion of sustainable development ideas. It is necessary to ensure high-quality training of teachers, as well as to provide an opportunity for their education throughout life, for the acquisition of competencies in continuing education programs. It is necessary to use such teaching methods that promote learning on the basis of competencies, and not just the transfer of knowledge. It can be such methods as: heuristic conversation, "brainstorming", role-playing and "business" games, trainings, casemethod, project method, group work with illustrative material (Learning for the future..., 2012).

Among other things, network communities, social activities, the study of all educational disciplines from the standpoint of ecology, and computer games are also noted. Obviously, out-of-class work and the work of children's associations of continuing education are currently the most accessible form of ESD.

Perhaps one of the reasons for the insufficient study of sustainable development issues in the framework of subject education is the lack or inaccessibility of the necessary teaching materials, which are available only for less than half $(34.5 \%)$ of the respondents. Moreover, in most cases $(64.2 \%)$, previously published manuals (non-fiction books or books for reading) are used; $28.3 \%$ of teachers have special educational and methodological complexes. The rest use materials published in the methodological journal, newspaper, collection (46.4\%), as well as developed independently or by colleagues (25.2 and $26.7 \%$ respectively).

In general, only $9.5 \%$ of teachers assess the level of their methodological training as sufficient for the implementation of ESD (56.1\% - insufficient, $28.4 \%$ found it difficult to answer). At the same time, would you like to improve your qualifications in ESD $78.4 \%$ of respondents; only 3 people $(1.4 \%)$ answered negatively, $16.2 \%$ found it difficult to answer. Among the preferred forms of continuing education are thematic continuing education courses on ESD (50.0\%); seminars, conferences (58.7\%); exchange of experience with colleagues, visiting open classes, master classes (58.6\%); independent study of methodological literature $(21.9 \%)$.

So, the results of a survey of teachers working in the field of ESD show that the ideas of sustainable development in the education system are generally perceived positively. However, the urgent need is for vocational training, advanced training of teachers for the implementation of ESD. 
This situation, of course, requires special attention and a completely different look at this problem appears; in our opinion, the need is for its solution through such proposed changes, such as:

- rethinking approaches to the organization of educational activities;

- redesigning the content of education;

- transition to productive methods, methods, technologies for organization educational activities;

- revision of approaches to the formation of teacher competencies.

Now consider the possibilities of solving these problems. Rethinking approaches to the organization of educational activities, considering the foregoing, should be based on:

- basic principles and certain values, underlying sustainable development;

- considering the features and patterns of interaction between nature, society and the economy;

- increased civic engagement in solving specific regional problems;

- development of environmentally oriented management to maintain and improve the quality of life;

- ensuring the integration of the content of educational subjects, educational programs;

- use of the potential of formal (mandatory), additional and informal (enlightenment) education;

- openness, considering the context of global change and local priorities;

- promoting transformation and transformation in the education system and in society.

- this is a gradual transition from education as preparation for economic life to education as the basis for creating a sustainable society, economy and environment; from education as a product (qualification) to education as a process of creating competence; from education as instruction to education as an accessory to learning.

We also need to make changes in the curriculum, content and learning process: from the curriculum as a final outline to the curriculum as experience, situational learning; from fixed knowledge to changing knowledge; from abstract knowledge to real knowledge; from a single learning model to multivariate learning models; from passive education to active learning; from lack of sustainable development to learning development ideas.

Such content is based on the key ideas of education for sustainable development. This is the idea of "the values of human life and safety in all surrounding environments (natural, social, technological, cultural, educational; the idea of human quality in all manifestations of his life; the idea of environmental quality; the idea of the value of human health and the health of the environment his surroundings; the idea of the quality of human life in the environment" (Keles, 2012).

To introduce education for sustainable development, a transition to productive methods and technologies for organizing educational activities, we need other learning models. These include: learning through discovery; cooperative learning; problem-integrative training; interdisciplinary training; learning based on critical thinking; training based on a system-activity approach.

To implement all of the above-mentioned methods for solving the problem, it is necessary to revise approaches to the formation of professional competencies of a teacher.

Experts developed approximate competencies of a teacher who can work in the context of education for sustainable development. These competencies correspond to three main characteristics: "a holistic approach focused on integrative thinking and practice; anticipation of change involving the study of alternative options for the future, learning from previous experience and the desire to participate in modern life; implementation transformations" (Pipere, Veisson, Salīte, 2015).

Thus, in the competency-based approach, content lines of education for sustainable development can be formed around "key (general cultural, educational, cognitive, informational, social-civic, communicative, personal competences); environmental, as well as specific for education for sustainable development (holistic approach, focused on integrative thinking and practice; anticipating changes, involving the study of alternative options for the future, learning from previous experiences and the desire to participate in modern life; implementing transformations) competencies." 
The main one is environmental competence, "designed to realize the biospheres function of mankind in the conservation and sustainable reproduction of life on Earth." From the point of view of N. Roczen, F.G. Kaiser, F.X. Bogner, M. Wilson "ecological competence, for example, of secondary school students allows put into practice the key principles of environmental education for sustainable development: the transition from abstract environmental problems to real ones, from global environmental problems to local ones, from environmental problems to personal environmental safety problems" (Roczen et al., 2014). This begs the question - what role does the teacher's environmental competence play in the context of education for sustainable development?

Education for sustainable development contributes to the reorientation of professional competencies. At the same time, such competence is necessary, which is not only special, narrowly subject, but encompassing all academic subjects, universal, cross-cutting for all subject teachers, since the ideas of sustainable development concern everyone. Cross-teacher environmental competence is the totality of all groups of teacher competencies, united by common ontological, epistemological and axiological foundations of a culture of sustainable development, which provide the ability of teachers of various specialties to solve the methodological and value-semantic problems of self-identification, self-determination, self-realization, self-development in a society striving for sustainable development. Such a cross-cutting (penetrating) ecological competence of a teacher will be focused on a continuous learning process, the study of complex problems related specifically to education for sustainable development.

Education for sustainable development can be seen as a common perspective, and as a process taking place in a changing world. The long-term goal is to live your life in the best possible order in a way that does not harm others, the environment and society in time, nor in space. At the same time, the ability to act is required from a specific person to achieve sustainable development, which implies the availability of appropriate knowledge, opportunities and motivation.

The task of the teacher is to help students achieve specific or set goals. Teachers working in different pedagogical conditions can use the following universal, according to the authors, didactic approaches (Girvan, Conneely, Tangney, 2016):

Student-centered - students are responsible for their learning and learn from their own experience and questions.

Process Oriented - focuses on relationships and systems. The main thing in learning process-oriented - the search for a solution to a problem, singly, or jointly, and not the result as such. Community and nature oriented - students get involved in events real life and everyday processes taking place in society.

Comprehensive - a single approach, including various objects and methods. An integrated approach involves obtaining knowledge about the environmental framework, systematization, energy flows, various waste management systems, relationships in nature and biological diversity, as well as knowledge about human needs, language, culture and creation.

School as a learning environment. A school is an "institution that teaches." The management of buildings and the surrounding area is an integral part of education.

Thus, in the competency-based approach, ESD content lines can be formed around the following competencies: key (general cultural, educational, cognitive, informational, social-civic, communicative, personal growth and development); environmental, as well as specific for ESD (learning from previous experience and desire to participate in modern life; implementation of transformations). The leading one is environmental competence.

A competency-based approach ensures the continuity of ESD at the level of general and vocational education. Latvia has developed a state educational standard for a school curriculum on "Environmental studies", which includes, for example, the formation of competencies, such as "the development of practical recommendations for nature conservation and sustainable development", "educational and methodological planning of environmental education and upbringing activities for sustainable development. At the level of university education, experience in the practical implementation of the competency-based approach is also applied. For example, Riga Technical University is implementing an environmental education curriculum. 
In the future, it is necessary to develop a model of specialist competencies in the field of sustainable development, and to develop a concept and technology for additional professional ESD.

The main result of education for sustainable development is a conscious socially significant activity aimed at harmonizing relations with the environment.

The immediate result of education for sustainable development should be an understanding of the need for not only environmental, but also socio-economic changes in economic management (on a global scale, individual states, regions, settlements, organizations and educational institutions) that strictly comply with environmental requirements.

The long-term result is the implementation of the axiological basis of education for sustainable development - post-material values (characterizing a society capable of replacing a consumer society), including: humanism, liberty, creation, moral, focus on dialogue and cooperation (rather than power, status and hierarchy), professionalism, self-realization, the quality of life; understanding of its role in nature and responsibility for its restoration and conservation for future generations.

Thus, education for sustainable development is built with an orientation on the features of post material civilization:

- decrease in the role of material production;

- development of production sectors that create services and information;

- increasing the role of knowledge and greater flexibility of the education system, corresponding to a society that responds promptly to changes in the environment and accordingly changes the management system.

The fundamental difference between planning in the context of sustainable development and planning, which tried to force the environment to be reconstructed to meet human needs, is to respond in a timely manner to deviation of environmental parameters (impact) by changes in the socio-economic system, which should be reflected in training courses.

\section{Conclusions}

Training teachers to educate future generations is a key factor in achieving the sustainable development goals. It is necessary to ensure high-quality training of teachers, as well as to provide an opportunity for their education throughout life, for the acquisition of competencies in continuing education programs. It is necessary to use such teaching methods (heuristic conversation, "brainstorming", role-playing and "business" games, project method, group work) that promote learning on the basis of competencies, and not just the transfer of knowledge.

According to the results of the survey, only $9.5 \%$ of teachers assess the level of their methodological training as sufficient for the implementation of ESD, more than half of the respondents consider their level of training insufficient, one third of the teachers were not able to evaluate their training. These results indicate that teachers rather critically assess their level of training and almost $80 \%$ would like to improve qualifications in ESD.

Among the preferred forms of continuing education are thematic continuing education courses on ESD seminars, conferences, exchange of experience with colleagues, visiting open classes, master classes and independent study of methodological literature. A survey of teachers working in the field of ESD shows that the ideas of sustainable development in the education system are perceived positively.

Education for sustainable development can be implemented in the form of training courses or their components, however, the most appropriate reorientation of the entire education system. The concept of sustainable development is to be able to play the role of an "umbrella" for various branches of knowledge, a system-forming factor in the education system, focused on solving existing and preventing new social, economic, and environmental problems. 


\section{Bibliography}

1. Cyrankowska M., Kostecka J., Mazur-Paczka A. (2019). The Role of Relationships in Teaching Content Important for Sustainable Development. In V. Dislere (Ed.), The Proceedings of the International Scientific Conference Rural Environment. Education. Personality. (REEP), 12. Jelgava: Latvia University of Life Sciences and Technologies, 34-39. doi: 10.22616/REEP.2019.004

2. Girvan G., Conneely C., Tangney B. (2016). Extending experiential learning in teacher professional development. Teaching and Teacher Education, 58, 129-139. doi: 10.1016/j.tate.2016.04.009

3. Hume T., Barry J. (2015). Environmental Education and Education for Sustainable Development. International Encyclopedia of the Social and Behavioral Sciences (2 ${ }^{\text {nd }}$ ed.), 733-739. doi: 10.1016/B978-0-08-097086-8.91081-X

4. Keles R. (2012). The Quality of Life and the Environment. Procedia - Social and Behavioral Sciences 35, 23-32. doi: 10.1016/j.sbspro.2012.02.059

5. Learning for the future: Competences in Education for Sustainable Development. (2012). United Nations Economic Commission for Europe Strategy for Education for Sustainable Development Retrieved from http://www.unece.org/fileadmin/DAM/env/esd/ESD_Publications/Competences_Publication.pdf

6. Lice-Zikmane I. (2018). Handicraft in the Context of Sustainable Education. In V. Dislere (Ed.), The Proceedings of the International Scientific Conference Rural Environment. Education. Personality. (REEP), 11. Jelgava: Latvia University of Life Sciences and Technologies, 296-303. doi: 10.22616/REEP.2018.036

7. National Reforms in School Education. (2019). Retrieved from https://eacea.ec.europa.eu/nationalpolicies/eurydice/content/national-reforms-school-education-34_en

8. Pipere A., Veisson M., Salīte I. (2015). Developing Research in Teacher Education for Sustainability: UN DESD via the Journal of Teacher Education for Sustainability. Journal of Teacher Education for Sustainability, 17(2), 5-43. doi: 10.1515/jtes-2015-0009

9. Policy Document for the Integration of a Sustainable Development Perspective into the Processes of the World Heritage Convention. (2015). World Heritage and Sustainable Development. Retrieved from https://whc.unesco.org/document/139747

10. Proposal for a Global Action Programme on Education for Sustainable Development as followup to the United Nations Decade of Education for Sustainable Development (DESD) after 2014. (2013). Retrieved from https://unesdoc.unesco.org/ark:/48223/pf0000224368

11. Roczen N., Kaiser F.G., Bogner F.X., Wilson M. (2014). A competence model for environmental education. Environment and Behavior, 46(8), 972-992. doi: 10.1177/0013916513492416

12. Rydén L., Migula P., Andersson M. (Eds.). (2003). Environmental Science: Understanding, protecting and managing the environment in the Baltic Sea Region. Uppsala: Baltic University Press. Retrieved from http://urn.kb.se/resolve?urn=urn:nbn:se:uu:diva-195717

13. Ten years of the UNECE Strategy for Education for Sustainable Development. Evaluation report on the implementation of the UNECE Strategy for Education for Sustainable Development from 2005 to 2015. (2016). New York and Geneva: United Nation. Retrieved from https://www.unece.org/fileadmin/DAM/env/esd/ESD_Publications/10_years_UNECE_Strategy_ for_ESD.pdf

14. The United Nations Conference on Sustainable Development, Rio+20. (2012). Retrieved from https://sustainabledevelopment.un.org/rio20

15. Transforming our world: the 2030 Agenda for Sustainable Development. (2015). United Nations. Retrieved from https://sustainabledevelopment.un.org/content/documents/21252030\%20Agenda $\% 20$ for\%20Sustainable\%20Development\%20web.pdf 